\title{
Ocular non-Hodgkin lymphoma: a report of two cases and review of the literature
}

\author{
R Paul ${ }^{1 凶}$, UK Kundu², E Kabir ${ }^{3}$, MN Islam
}

\begin{abstract}
In this article, two cases of non-Hodgkin lymphomas (NHL) occurring at an unusual site were reported. The first case was a male patient aged 60 years hailing from Debidwar, Comilla came with the complaint of gradually increasing mass in the left eyelid for two years. Fine-needle aspiration (FNA) and histopathology of his lesion revealed NHL, which on immunohistochemistry showed to be of B-cell origin. A debulking operation was done in National Institute of Ophthalmology \& Hospital, Dhaka and he was sent for chemotherapy. The second case was also a male aged 35 years from Muladi, Barisal who presented with gradually increasing bilateral masses on both the upper eyelids for six months. The results of FNA of the eyelid tumors were suggestive of NHL that was subsequently confirmed by histopathology. Immunohistochemistry showed the tumor to be of B-cell origin.
\end{abstract}

Keywords: ocular lymphoma, non-Hodgkin lymphoma, histopathology, immunohistochemistry.

\section{Introduction}

Depending on the site of involvement, ocular lymphoma can be either intraocular or orbital and adnexa. Hodgkin lymphoma (HL) very rarely causes ocular disease; non-Hodgkin lymphoma (NHL) is the most common type of ocular lymphoma. Ocular adnexal lymphomas are non-Hodgkin B cell lymphomas and by definition are extranodal lymphomas. ${ }^{1}$ Ocular adnexal lymphoid tumors may involve the eyelids, conjunctiva, orbital connective tissue, or lacrimal structures. Pathological diagnosis is based on routine light microscopy supported by immunohistochemical staining or molecular genetic analysis to identify lineage. ${ }^{2}$

Lymphomas arising at extranodal sites are relatively common accounting for between
$24.0 \%$ and $48.0 \%$ of lymphomas. ${ }^{3,4}$ Lymphoproliferative disease of the orbit usually presents later in life and causes symptoms due to the effect of gradually increasing mass effect. Proptosis and visible conjunctival mass are the common modes of presentation. It tends to be localized to the orbit at the time of diagnosis and responds well to local or systemic therapy. ${ }^{5}$

Chemoradiation is the most effective treatment. Lymphoma has been described as the most common malignant orbital tumor, representing $55.0 \%$ of cases in adults and $10.0 \%$ of cases in older patients. ${ }^{6-8}$

We have reported here two cases of ocular $\mathrm{NHL}$, one was 60 years old and another one was 35 years old male.

\footnotetext{
1. R Paul, Assistant Professor, Department of Pathology, Ibrahim Medical College, Dhaka. Email: ritapaul16@gmail.com

2. UK Kundu, Assistant Professor of Ophthalmology, Mugda Medical College, Dhaka

3. E Kabir, Professor, Department of Pathology, Sir Salimullah Medical College, Dhaka

4. MN Islam, Professor and Head, Department of Pathology, Sir Salimullah Medical College, Dhaka
} 
Case reports

\section{Case 1}

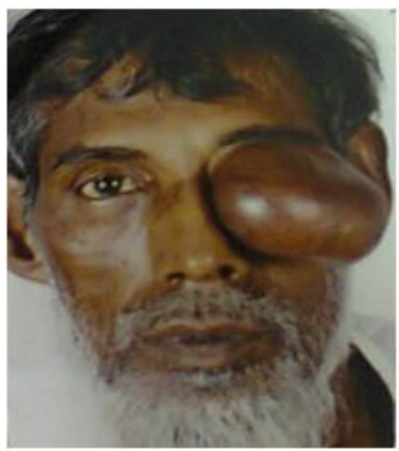

Fig. 1. Case 1.

A male 60 years old, hailing from Debidwar, Comilla, presented to the outpatient department of National Institute of Ophthalmology and Hospital (NIOH), Dhaka with the complaints of gradually increasing painless swelling on the left upper eyelid for 2 years (Fig. 1). On examination, the lesion was $6 \mathrm{~cm} \times 5 \mathrm{~cm}$ in diameters and firm in consistency. On fine-needle aspiration (FNA), some whitish material came out. Then histopathology (Fig. 2) and immunohistochemistry (Fig. 3) were done and the results were in support of the diagnosis $\mathrm{NHL}$ of $\mathrm{B}$-cell origin. All other relevant investigations were done including complete blood count (CBC), bleeding time (BT), clotting time (CT), and random blood sugar (RBS), electrocardiography (ECG), chest $X$-ray posteroanterior $(P / A)$ view and were found to be unremarkable.

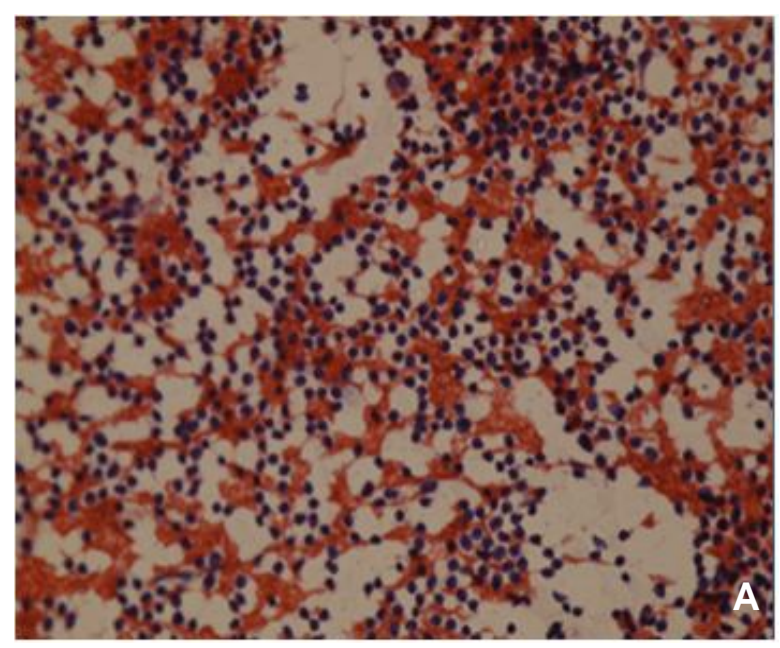

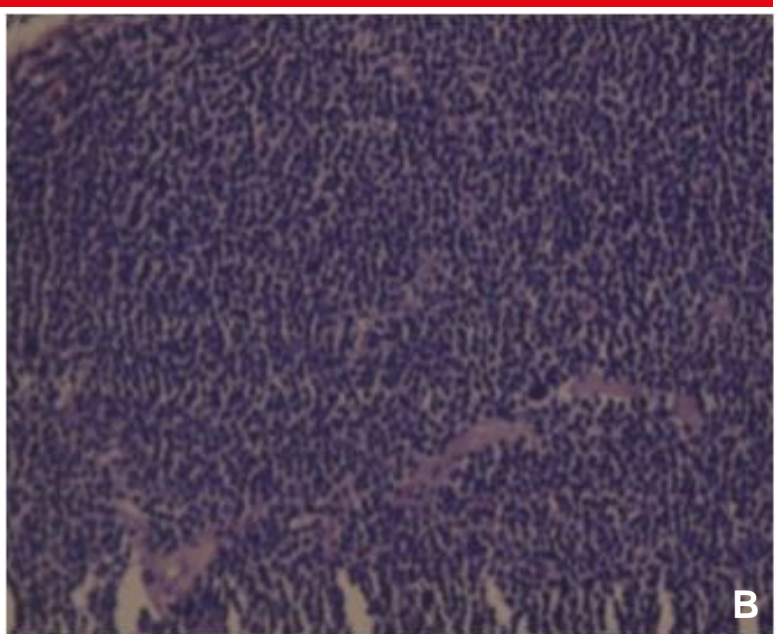

Fig. 2. Histopathology from the sample of the Case 1. A. Photomicrograph showing the monomorphous population of atypical lymphoid cells, scanty cytoplasm with clumped chromatin. (PAP, x200). B. Photomicrograph showing the hypercellular proliferations. Most of the tumor cells are monotonous in appearance, having large nuclei with condensed chromatin. (H\&E, x400).
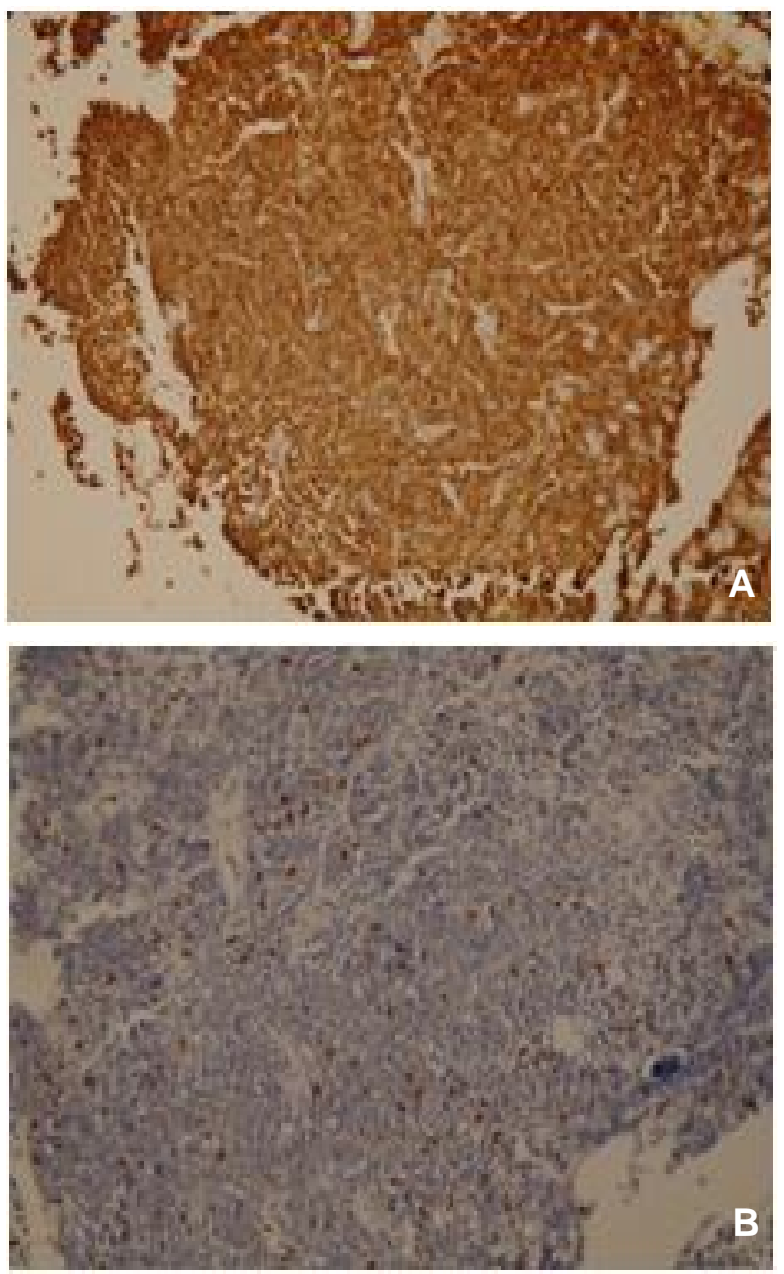


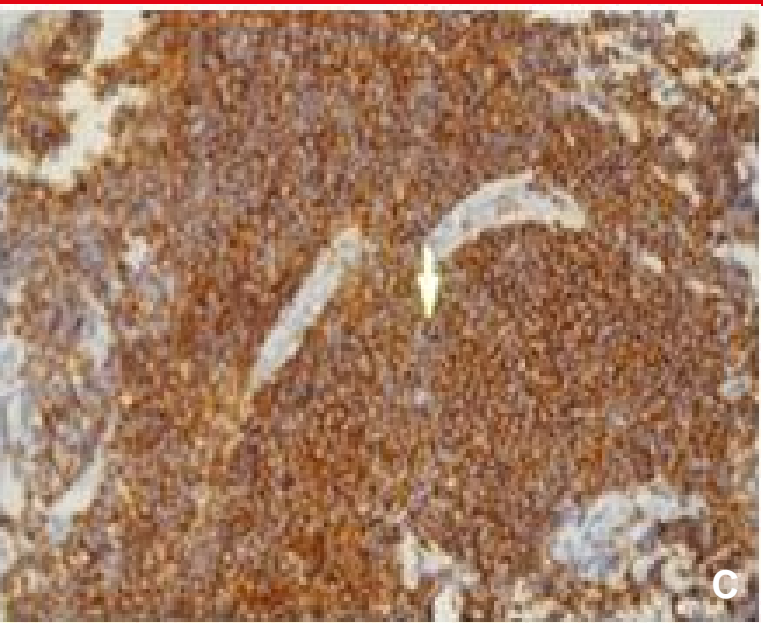

Fig. 3. Immunostaining from the sample of the Case 1. A. Photomicrograph of immunohistochemistry study showing lymphoid cells with positive staining for the leukocyte common antigen. (IHC, x400). B. Photomicrograph of immunohistochemistry study showing scattered lymphoid cells with positive staining for CD3. (IHC, x400). C. Photomicrograph of immunohistochemistry study showing the majority of atypical lymphoid cells with positive staining for CD20. (IHC, $x$ 400).

\section{Case 2}

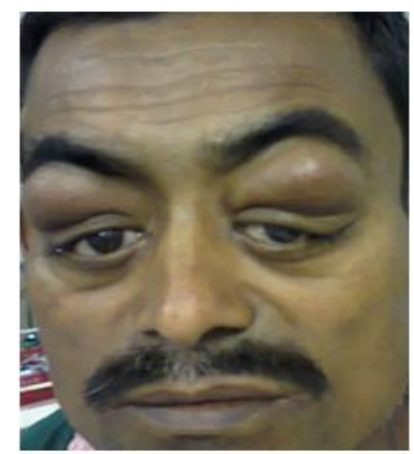

Fig. 4. Case 2.

A male aged 35 years from Muladi, Barisal presented with gradually increasing mass on both the upper eyelids for six months (Fig. 4). He presented to the outpatient department of $\mathrm{NIOH}$, Dhaka. The tumor was firm in consistency. FNA, histopathology (Fig. 5) and immunohistochemistry (Fig. 6) were done and were done and the results were in support of the diagnosis NHL of B-cell origin.
Other relevant investigations including $\mathrm{CBC}$, $B T, C T, R B S$, and chest $X$-ray $P / A$ view were within normal limit.
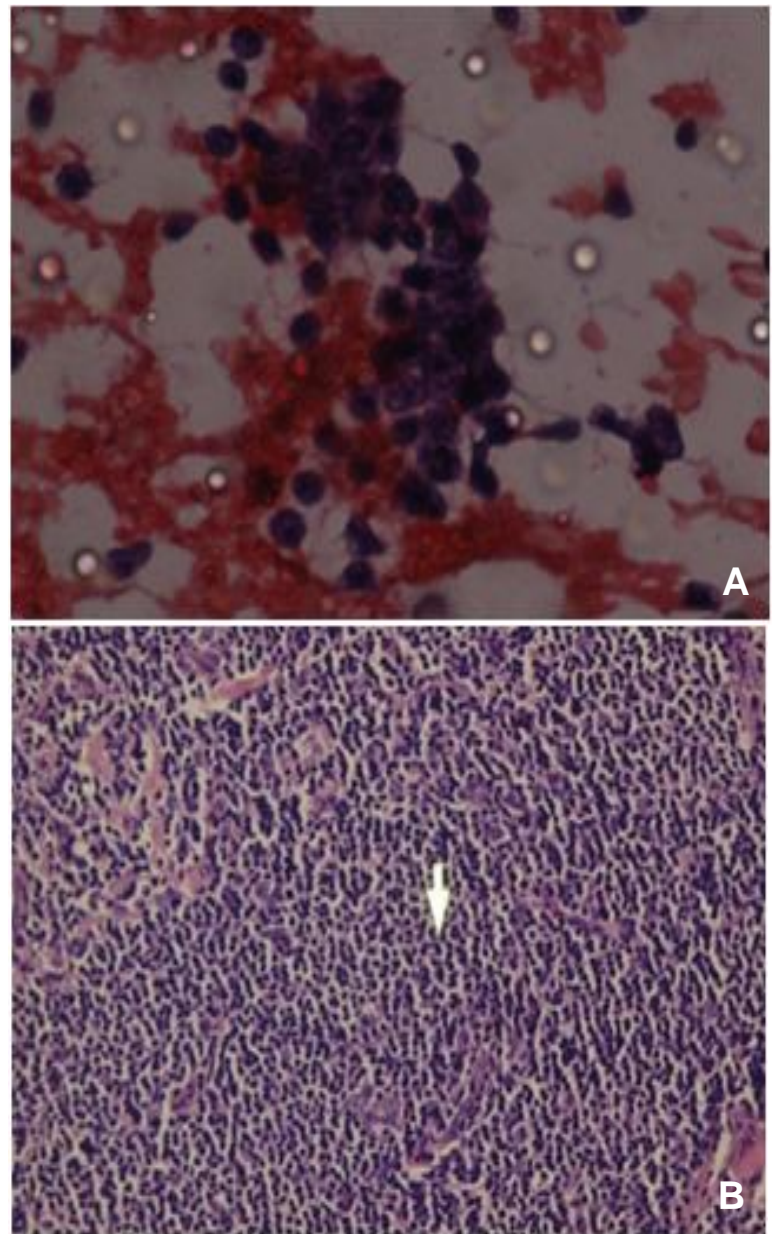

Fig. 5. Histopathology from the sample of the Case 2. A. Photomicrograph showing the monomorphous population of atypical lymphoid cells, scanty cytoplasm with clumped chromatin. (PAP, x200). B. Photomicrograph showing the hypercellular proliferations. Most of the tumor cells are monotonous in appearance, having large nuclei with condensed chromatin. (H\&E, x200).

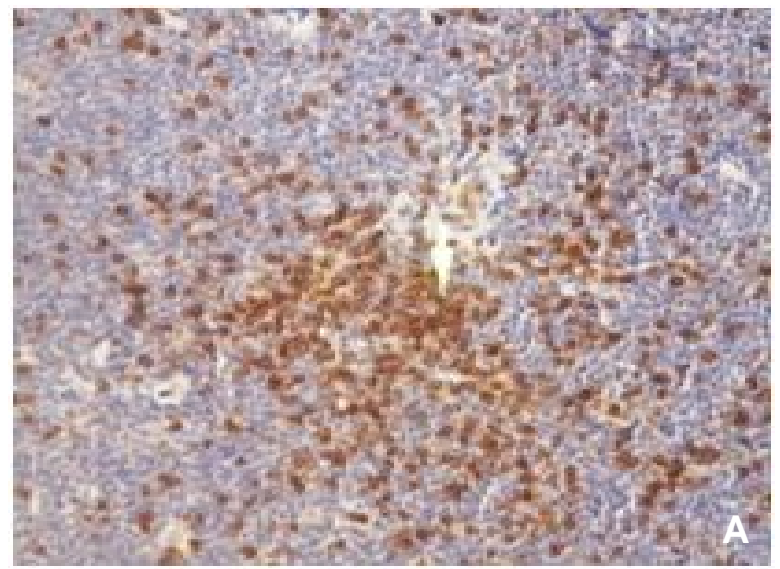




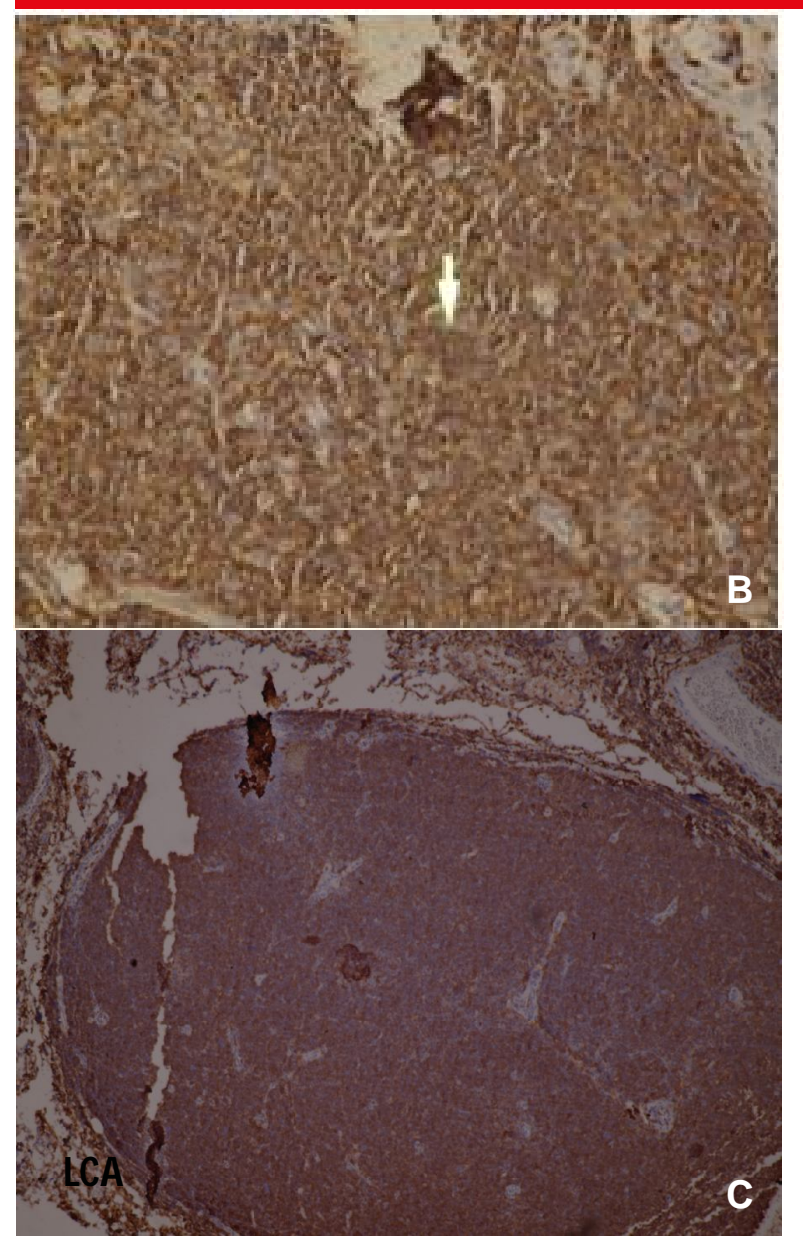

Fig. 6. Immunostaining from the sample of the Case 2. A. Photomicrograph of immunohistochemistry study showing scattered lymphoid cells with positive staining for $C D 3$. (IHC, x400). B. Photomicrograph of immunohistochemistry study showing majority of atypical lymphoid cells with positive staining for CD20. (IHC, x400). C. Photomicrograph of immunohistochemistry study showing lymphoid cells with positive staining for leukocyte common antigen. (IHC, x400).

\section{Discussion}

The incidence of lymphoproliferative ocular diseases, especially malignant lymphoma, has increased over the years. Lymphoma is the most common primary malignant orbital tumor in Asian countries like Japan and Korea. ${ }^{9-11}$

As well as in Europe, the incidence of ocular lymphoma increases with advancing age. ${ }^{12,13}$ Intraocular lymphoma typically affects elderly patients, with reported series having mean ages in the seventh decade of life. The median age at presentation for orbital and adnexal lymphoma is older than 60 years. In a study conducted in the United States, malignant lymphoma was the most common orbital tumor in the elderly age group, accounting for $24.0 \%$ of cases. ${ }^{14}$ But in the present study, one aged 35 years and the other 60 years old. These cases were in younger age comparative to the mentioned study.

On initial presentation, orbital adnexal lymphoma is either unilateral or bilateral, but ultimately, $80.0-90.0 \%$ of patients had bilateral involvement. ${ }^{15-18}$ In our study one had unilateral and the other had bilateral.

\section{Cytological feature}

Smears show a monomorphous population of atypical lymphoid cells, scanty cytoplasm with clumped chromatin. ${ }^{19}$

\section{Histological features}

Hypercellular proliferations are seen with sparse stroma. ${ }^{20}$

\section{Immunohistochemistry}

Immunological identification of cell surface markers on lymphocytes can be used to classify tumors as containing $\mathrm{T}$ - or B-cells and as being monoclonal or polyclonal in origin. The vast majority of orbital lymphomas are of B-cell origin with monoclonal proliferation from a single neoplastic cell. ${ }^{21}$

\section{Treatment}

As for other extranodal forms of lymphoma, the treatment of ocular adnexal lymphoma depends on the stage and histological classification. For isolated ocular adnexal lymphoma (stage IE) of low grade, externalbeam radiation therapy is considered the standard therapy. ${ }^{22}$ For more widespread disease or for higher-grade lymphomas, systemic chemotherapy or a combination of chemotherapy and radiation therapy may be more appropriate. ${ }^{23}$ Another alternative for stage IE low-grade lymphoma of the ocular adnexa, particularly low-grade B-cell follicular lymphoma or mucosa-associated lymphoid tissue lymphoma, may be monoclo- 
nal antibody therapy. ${ }^{24}$

The incidence of malignant lymphoma was $25.0 \%$ (3 of 12 malignant tumors). The ratio seemed to be higher comparing to previous reports as $2.6-18.3 \% .^{25}$ In the present study, $2(2.4 \%$, out of 85$)$ cases were cytopathologically and histopathologically diagnosed as $\mathrm{NHL}$ and immunohistochemically confirmed as NHL B-cell origin. It revealed lymphoid cells showing positive staining for leukocyte common antigen, scattered lymphoid cells positive staining for CD3 and majority of the atypical lymphoid cells showing positive staining for CD20.

\section{Conclusion}

The rate of lymphoma is increasing worldwide. In Bangladesh, it is detected frequently due to improved facilities. It is an alarming scenario. So, we should be alert. Early detection will save and/or prolong patients' life.

\section{References}

1. Stansfeld AG, Diebold $\mathrm{J}$, Noel $\mathrm{H}$, et al. Updated Kiel classification for lymphomas. Lancet 1988;1(8580):292-3.

2. Nadler LM. The malignant lymphomas. In Harrison's Principles of Internal Medicine. Braunwald $E$, et al., editors, 12th ed. McGraw-Hill: New York), 1991 ;pp.1599612.

3. Freeman C, Berg JW, Cuttler SJ. Occurrence and prognosis of extranodal lymphomas. Cancer 1972;29(1):252-60.

4. Banfi A, Bonadonna G, Carnevali G, Oldini C, Salisni E. Preferential sites of involvement and spread of malignant lymphoma. Eur J Cancer 1968;4:319-24.

5. Ahmed S, Shahid RK, Sison CP, Fuchs A, Mehrotra B. Orbital lymphomas: a clinicopathologic study of a rare disease. Am J Med Sci 2006;331(2):79-83.

6. Valvassori GE, Sabnis SS, Mafee RF, Brown MS, Putterman A. Imaging of orbital lymphoproliferative disorders. Radiol Clin North Am 1999;37(1):135-50.

7. Shields JA, Shields CL, Scartozzi R. Survey of 1264 patients with orbital tumors and simulating lesions: The 2002 Montgomery Lecture, part 1. Ophthalmology 2004;111(5):997-1008.
8. Bonavolontà $G$, Strianese $D$, Grassi $P$, et al. An analysis of 2,480 space-occupying lesions of the orbit from 1976 to 2011. Ophthal Plast Reconstr Surg 2013;29(2):79-86.

9. Ohtsuka K, Hashimoto M, Suzuki Y. High incidence of orbital malignant lymphoma in Japanese patients. Am J Ophthalmol 2004;138(5):881-2.

10.Shikishima K, Kawai K, Kitahara K. Pathological evaluation of orbital tumours in Japan: analysis of a large case series and 1379 cases reported in the Japanese literature. Clin Exp Ophthalmol 2006;34(3):239-44.

11. Ko YH, Kim CW, Park CS, et al. REAL classification of malignant lymphomas in the Republic of Korea: incidence of recently recognized entities and changes in clinicopathologic features. Hematolymphoreticular Study Group of the Korean Society of Pathologists. Revised European-American lymphoma. Cancer 1998;83(4):806-12.

12.Seregard S, Sahlin S. Panorama of orbital space-occupying lesions. The 24-year experience of a referral centre. Acta Ophthalmol Scand 1999;77(1):91-8.

13.Moslehi R, Devesa SS, Schairer C, Fraumeni JFJr. Rapidly increasing incidence of ocular non-hodgkin lymphoma. J Natl Cancer Inst 2006;98(13):936-9.

14.Demirci H, Shields CL, Shields JA, Honavar SG, Mercado GJ, Tovilla JC. Orbital tumors in the older adult population. Ophthalmology 2002;109(2):243-8.

15.Char DH, Ljung BM, Miller T, Phillips T. Primary intraocular lymphoma (ocular reticulum cell sarcoma) diagnosis and management. Ophthalmology 1988; 95(5):625-30.

16.Char DH, Margolis L, Newman AB. Ocular reticulum cell sarcoma. Am J Ophthalmol 1981;91(4):480-3.

17.Whitcup SM, de Smet MD, Rubin BI, et al. Intraocular lymphoma. Clinical and histopathologic diagnosis. Ophthalmology 1993;100(9):1399-406.

18.Peterson K, Gordon KB, Heinemann MH, DeAngelis LM. The clinical spectrum of ocular lymphoma. Cancer 1993; 72(3):843-9. 
19.Pugh WC, Manning JT, Butller JJ. Paraimmunoblastic variant of small lymphocytic lymphoma/leukemia. Am J Surg Pathol 1988;12:907-17.

20.Coupland SE, Krause L, Delecluse HJ, et al. Lymphoproliferative lesions of the ocular adnexa. Analysis of 112 cases. Ophthalmology 1998;105(8):1430-41.

21. Lauer SA. Ocular adnexal Iymphoid tumors. Curr Opin Ophthalmol 2000;11:361-6.

22.Platanias LC, Putterman AM, Vijayakumar S. Treatment and prognosis of orbital non-Hodgkin's lymphomas. Am J Clin Oncol 1992;15:79-83.
23.Fung CY, Tarbell NJ, Lucarelli MJ. Ocular adnexal lymphoma: clinical behavior of distinct World Health Organization classification subtypes. Int J Radiat Oncol Biol Phys 2003;57:1382-91.

24.Toshida $\mathrm{H}$, Mamada N, Fujimaki T, et al. Incidence of benign and malignant eyelid tumors in Japan. Int $\mathrm{J}$ Ophthalmic Pathol 2012;1(2):112-14.

25.Deprez M, Uffer S. Clinicopathological features of eyelid skin tumors. A retrospective study of 5504 cases and review of literature. Am J Dermatopathol 2009;31(3):256-62.

\section{Suggestion for citation of the above:}

Paul R, Kundu UK, Kabir E, Islam MN. Ocular non-Hodgkin lymphoma: a report of two cases and review of the literature. Mediscope 2018;5(2):36-41. 